\title{
Time estimation and time perceiving in patients receiving intravenous anaesthesia for endoscopic procedures
}

\author{
Włodzimierz Płotek', Małgorzata Sobol-Kwapinska², Marcin Cybulski ${ }^{3}$, Anna Kluzik, \\ Małgorzata Grześkowiak ${ }^{5}$, Leon Drobnik ${ }^{6}$ \\ ${ }^{1}$ Department of Teaching Anaesthesiology and Intensive Therapy, Poznan University of Medical Sciences, Poland \\ ${ }^{2}$ Department of Personality Psychology, The John Paul II Catholic University of Lublin, Poland \\ ${ }^{3}$ Department of Clinical Psychology, Poznan University of Medical Sciences, Poland \\ ${ }^{4}$ Department of Anaesthesiology, Intensive Therapy and Pain Treatment, Poznan University of Medical Sciences, Poland \\ ${ }^{5}$ Department of Teaching Anaesthesiology and Intensive Therapy, Poznan University of Medical Sciences, Poland \\ ${ }^{6}$ Department of Anaesthesiology, Intensive Therapy and Pain Treatment, Professor, Poznan University of Medical \\ Sciences, Poland
}

\begin{abstract}
Introduction. The basic goals of the study were to analyze how patients receiving intravenous anaesthesia for endoscopy produce one-minute time intervals after anaesthesia, and to characterize the relationship between attitude towards time and the production of one-minute intervals.

Material and methods. Twenty four intravenously anesthetized patients constituted the Anaesthesia Group and 25 nonanesthetized patients formed the Control Group. The Mini-Mental State Examination and the Sense of Coherence Meaningfulness Subscale were used to recognize the problem of dementia and depression, the Time Metaphors Questionnaire was used for the assessment attitudes toward time. Time production of one-minute was measured three times in each of four sessions.

Results. The tested participants of both groups shortened the one-minute intervals. Duration of anaesthesia did not affect the time production. Perceiving time as empty and meaningless was related with misestimating time after colonoscopy.

Conclusions. Time interpretation by using metaphors and time production are related with each other.
\end{abstract}

Keywords: time perception, time metaphors, anaesthesia, endoscopy.

\section{Introduction}

Emotions and cognition are tightly bound entities that have clear functional and organic basis [1]. Both of them can be disturbed in hospitalized patient. Negative emotions, like fear and anxiety influence the patients undergoing anaesthesia regardless of age, and this impact has been extensively discussed in the literature [2-4]. On the other hand, cognition is affected by perioperative stress and anaesthesia influencing the quality of life which has also been well described by Steinmetz et al. [5]. Emotions and cogni- tion are also engaged in the process of time production [6]. We know from the previous studies that anxiety and depression affect the intestinal motor function $[7,8]$. These facts inspired us to construct the study assessing the relationship between emotional and cognitive aspect of time perception in relation to intravenous anaesthesia for endoscopic procedures. Especially that brain regions responsible for the interval timing (corticostriatal circuits and dopamine neurons) are closely related to cognitive phenomena and can be discussed as a part of human cognitive func- 
tioning (working memory, motor functions, decision making, etc.) [9].

The aim of the study was to analyze the impact of receiving intravenous anaesthesia for endoscopic procedures on producing one-minute intervals of time, and to assess the connection between perceiving time before anaesthesia and the production of one-minute interval after colonoscopy.

Our study poses the following main research questions: 1) What influence do anaesthetics administered during colonoscopy exert on the generation of the one-minute time interval?; 2) Does the manner patients perceive time prior to colonoscopy have any relation to generating one-minute time interval following the procedure?

Colonoscopy is a highly invasive, stress-inducing diagnostic procedure. It is a procedure which in a controlled and reversible way results in sleep, retrograde amnesia, analgesia and the inhibition of sympathetic reflexes. The substances used for this kind of anaesthesia impair psychophysical functions for a few hours after their administration [10]. We suggested the hypothesis that patients after anaesthesia could develop alterations in perception of time when compared to nonanaesthetized controls.

The patient's attitude to diagnostic and treatment procedures, as well as their approach towards the time spent in hospital and the relations with medical personnel, are of utmost importance in therapy. Negative emotional state, especially severe anxiety, may considerably hinder the treatment, to the extent that it can even render certain treatment or diagnostic procedures to be impossible to perform [7]. Since one's attitude to time is closely related to one's emotional state [11-16], and to approach to the treatment $[17,18]$ it may be assumed that the perceiving of time shall be closely linked to the manner in which the patient's psyche deals with experiencing a serious diagnostic procedure and the recovery following it. Hence, we assume that patients who evaluate time in a negative way will more considerably misestimate time after a diagnostic procedure under anaesthesia.

\section{Material and methods}

This study was performed with permission from the local bioethical committee (Bioethical Committee of Poznan Medical University, Permission No. 427/10, May 6, 2010). Patients gave written consent for participation in the study.

The following psychological tests were used during the study.
The Time Production Method of time duration judgement was used [19]. The estimation of time intervals is interpreted psychologically through the functioning of the inner clock the human being is equipped with. Additionally, estimating the duration is perceived as a cognitive construct under the influence of attention and memory [20]. From the neuropsychological perspective it should be stressed that there are a number of mechanisms involved in the process of time estimation, as well as various regions of the human brain: the cerebellum ('automatic system'), the prefrontal cortex, the lower part of the parietal lobes ('cognitive system') and the basal ganglia (mainly striatum), the thalamus and the anterior cingulate cortex. These structures are related to other cognitive functions, such as attention, memory, visual-spatial coordination or language skills. The presented systems operate simultaneously [9], their functioning may be disturbed by, among others, the effect of psychoactive substances (drugs or medicines) [21-23].

Time production of one-minute was measured by means of a stopwatch three times in each of the sessions: initial, 1.5, 3, and 6 hours after anaesthesia. The participants of the study were asked to produce one-minute intervals three times. The examiner said 'start' to the participant and the tested patient was asked to say 'stop' once one minute of time had passed. The participant was not instructed whether or not to count in silence.

The perceiving of time was assessed with the Time Metaphors Questionnaire (TMQ) [24]. This questionnaire is composed of ten scales. The Constructive Time (CT) scale (alpha =.93, 20 items) contains items which describe time as directed towards the truth and the achievement of goals (for example, 'Time is a way to put plans in operation'). The Friendly Time (FT) scale (alpha $=.86,12$ items) characterizes time as a friend and a teacher (for example, 'Ever-ageing time teaches all things'). The Awareness of Mortality (AM) scale (alpha $=.84,9$ items) includes metaphors of time as finite (for example, 'Time is an incurable disease'). The Hostile Time (HT) scale (alpha =.86, 10 items) describes time as a disappointment and an enemy (for example, 'Time is a disappointment'). The Confusion in Time (CO) scale (alpha $=.82,9$ items) characterizes time in terms of a power which is out of control (for example, 'Time flows beside me'). The Rapid Passage of Time (RP) scale (alpha $=.85,10$ items) includes metaphors representing time as a speedy vehicle (for example, 'Time flies like an arrow'). The Significance of the Moment (SM) scale (alpha $=.77,7$ items) includes metaphors indicating the 
necessity of making the most of each moment of life (for example, 'Each moment is worth one's weight in gold'). The Chaotic Time $(\mathrm{CH})$ scale (alpha $=.80$, seven items) consists of items describing time as turbulent (for example, 'Time is like a stormy ocean'). The Subtle Time (ST) scale (alpha $=.79$, six items) characterizes time as peaceful (for example, 'Time is like incense smoke'). The Empty Time (ET) scale (alpha $=.67$, five items) describes time as boredom (for example, 'Time is like a drowsy afternoon').

The participants have to indicate 'how they imagine time' [24] on a four-point scale ranging from 'very appropriate' to 'very inappropriate'. Results of the research indicated that people high in Extraversion, Openness, Agreeableness, Conscientiousness and low in Neuroticism (measured by NEO-FFI by Costa, McCrae) generally evaluated time positively (high score on Constructive Time, Friendly Time, Significance of the Moment, Subtle Time). In turn participants with high score on Neuroticism scale perceive time usually as speed, wild and chaotic [12]. Friendly Time scale correlate positively with realization of aims. Negative time evaluation was linked with time pressure, fatalism and hedonism measured by Time Perspective Questionnaire AION-2000, Nosal \& Bajcar [12]. Relation between TMQ and PANAS (The Positive and Negative Affect Schedule, Watson, Clark and Tellegen) indicated that perceiving time as friendly and constructive were linked with positive emotions, and conceiving time as enemy were connected with negative emotions. There were no significance correlations between positive evaluation of time and negative emotions [24]. Time Constructive and Time Friendly scales correlated positively with a quality of life measured by CASP-19 by Higgs and others [25] and with the purpose in life measured by Noo-Dynamics by Popielski [26].

The Mini-Mental State Examination (MMSE) [27] was used to recognize the problem of dementia, which was the major exclusion criterion. This method is a well-known test used for the screening of cognition in depressed patients and for diagnosing cognitive dysfunction, mainly towards dementia. The Polish MMSE version normalized by Stańczak [28] was used in this study (alpha $=.88 ; 30$ items).

The Meaningfulness Subscale (MS) from the Sense of Coherence Scale (M-SOC) [29] was used as a method for recognizing the problem of depression - the second major exclusion criterion [30,31]. This subscale is composed of eight items. It measures the level of feeling towards important fields of life worth emotional involvement and energy expenditure. The answers to the statements are scored on a 7-point scale. The Polish M-SOC version was used in this study (alpha $=.71$ ) [32].

All tests were performed in standardized conditions (air-conditioned quiet room with constant artificial light, similar time of a day).

Between June and September 2010, 40 patients hospitalized in the clinics of the Poznan University of Medical Sciences, were enrolled in the study: 24 (16 women and 8 men) who underwent a colonoscopy under intravenous anaesthesia constituted the Anaesthesia Group and 25 patients (19 women and 6 men) who did not receive such treatments formed the Control Group. To exclude those with pre-existing cognitive disturbances and depression, a screen was performed using the Mini-Mental State Examination (MMSE $\geqslant 24$ pts) and Sense of Coherence Meaningfulness Subscale (M-SOC = 34 pts) $[30,31,33]$. Patients in Anaesthesia Group and Control Group were asked to participate in the study and give their informed consent. Patients were clinically examined by a physician with regard to dehydration, ion imbalances (potassium and sodium), severe anaemia $(\mathrm{Hb}=10 \mathrm{mg} / \mathrm{dL})$, and thyroid dysfunction; the presence of any of these pathologies was a criterion for exclusion. The Anaesthesia Group patients were premedicated with oral midazolam 0.1$0.15 \mathrm{mg} / \mathrm{kg}$ and transferred to the operating room. If the patients were anxious before the procedure, additional sedation was induced with midazolam 1-2 mg iv (Midazolam, WZF Polfa). Patients were anesthetized using intravenous propofol (Plofed 1\%, WZF Polfa) 1-2 $\mathrm{mg} / \mathrm{kg}$ was used. Analgesic doses of fentanil (Fentanyl, WZF Polfa) $1-2 \mu \mathrm{g} / \mathrm{kg}$ iv were used. During the anaesthesia, vital signs were monitored, and $1000 \mathrm{ml}$ Sterofundin (Braun) was infused continuously to prevent dehydration. Vital signs were recorded and no adverse events were observed.

\section{Statistical analysis}

Statistical analysis was performed using PASW Statistics v.19 (2011) for Windows. The demographic data, results on $\mathrm{TMQ}$, time production and the duration of anaesthesia were presented as mean with standard deviation (SD). The differences in demographic data between the participants of the groups, time production test, TMQ and the relationship between the duration of anaesthesia and the production of one-minute intervals were tested by $t$-test and $p=0.05$ was considered statistically significant. The results on the time production test were analyzed in the parallel sessions 
between the groups as well as between the consecutive sessions within the groups. Correlation between TMQ and Time Production results were analyzed by Pearson's coefficient and $p=0.05$ was considered statistically significant.

\section{Results}

\section{Demographic characteristics}

The demographic characteristics are presented in Table 1.

The groups did not differ in terms of the demographic characteristics. General level of scholar education in studied participants has been various: ten (AG: 7, CG: 3) received primary education, 25 (AG: 11, CG: 14) received secondary education and 14 subjects (AG: 11, CG: 3) received higher education.

The patients did not present pre-existing cognitive disturbances when screened with MMSE. The results on M-SOC did not differ between the groups and were above 40 points, which is adequate to a range for mean population (t-test; $p=0.05$ ) [31].

Time production of one-minute interval in three trials

Table 2 presents mean results of generating one-minute time intervals in the Anaesthesia Group and the Control Group, as well the differences between them measured by means of the t-test. In order to analyse the degrees of misestimation of one-minute time intervals, the results (that is, the numbers of seconds estimated by the subjects to represent one minute) were converted into a time interval misestimation ratio defined as the absolute difference between 60 seconds and the number of seconds reported by the subjects. All mean 1-minute intervals produced by the participants of both groups were shorter than the real dura- tion. There were no significant differences between the time intervals generated by the groups of hospitalized patients. There were also no significant differences in the time misestimations between the Anaesthesia Group and the Control Group. There were, however, significant differences in the time misestimations between the group of patients who received midazolam immediately prior to colonoscopy $(\mathrm{N}=11)$ and the group of patients who did not receive this substance $(N=13)$. Significant differences $(p<.05)$ occurred in two trials prior to the procedure and in two trials 1.5 hour following it. The patients who had been administered midazolam were less accurate in generating the one-minute interval in comparison with the patients who had not received it. The generation of one-minute intervals did not differ between the groups in the trials 3 and 6 hours after the procedure.

The influence of the anaesthesia duration on the production of one-minute intervals

The duration of anaesthesia was 10-60 min. (mean $36.74 \mathrm{~min} ;$ SD 12.76). By t-test, we analyzed the relationship between the results on the production of the one-minute intervals and the duration of anaesthesia. We observed no statistically significant relationships ( $p=0.05)$. There were no significant connection between the degrees of misestimation on the length of anaesthesia.

TMQ scales relating to one-minute time production The correlation coefficient between the degree of misestimations in the generation of time intervals and the conception of time in metaphors was calculated. In the Anaesthesia Group there was one significant correlation $(r=.47, p<.05)$ between the Empty Time scale results and the degree of misestimations in the gen-

Table 1. Characteristics of the study group (age, height, BMI)

\begin{tabular}{lcc}
\hline & $\begin{array}{c}\text { Anaesthesia Group } \\
\mathrm{N}=24,16 \text { women, 8 men }\end{array}$ & $\begin{array}{c}\text { Control Group } \\
\mathrm{N}=25,19 \text { women, 6 men }\end{array}$ \\
\hline Minimum age & 20 & 19 \\
\hline Maximum age & 77 & 75 \\
\hline Mean age (M) & 42.46 & 42.96 \\
\hline Age-standard deviation (SD) & 16.83 & 17.18 \\
\hline Minimum height & 145 & 152 \\
\hline Maximum height & 182 & 195 \\
\hline Mean height (M) & 165.54 & 166.64 \\
\hline Height-standard deviation (SD) & 10.25 & 10.37 \\
\hline Minimum BMl & 17 & 17 \\
\hline Maximum BMl & 38 & 35 \\
\hline Mean BMI (M) & 23.17 & 23.13 \\
\hline BMl-standard deviation (SD) & 5.49 & 5.48 \\
\hline
\end{tabular}


Table 2. Mean scores (M), standard deviations (SD) of the results of the Time Production Method (TP) and the degrees of time misestimation (TPZ), as well as differences between them (t-test) in the AG and the CG

\begin{tabular}{|c|c|c|c|c|c|}
\hline & \multicolumn{2}{|c|}{$A G(N=24)$} & \multicolumn{2}{|c|}{$\mathrm{CG}(\mathrm{N}=25)$} & \multirow[b]{2}{*}{$\mathrm{t}$} \\
\hline & $M$ & SD & $M$ & SD & \\
\hline TPIO & 49.83 & 21.38 & 43.83 & 18.17 & 6 \\
\hline TP $\| 0$ & 52.35 & 20.92 & 47.14 & 18.17 & 5.21 \\
\hline TP III0 & 52.25 & 20.44 & 47.14 & 16.81 & 5.11 \\
\hline TPI 1.5 & 44.28 & 21.35 & 40.51 & 18.07 & .24 \\
\hline TP II 1.5 & 47.25 & 20.26 & 43.07 & 18.5 & .42 \\
\hline TP III 1.5 & 49.55 & 21.51 & 44.98 & 19.56 & .65 \\
\hline TP I 3 & 47.09 & 17.26 & 45.30 & 13.62 & 1.79 \\
\hline TP $\| 3$ & 51.21 & 18.76 & 50.11 & 17.17 & 1.1 \\
\hline TP III 3 & 51.45 & 19.22 & 51.23 & 16.70 & .22 \\
\hline TPI 6 & 47.38 & 15.40 & 48.98 & 16.26 & -1.61 \\
\hline TP $\| 6$ & 49.14 & 14.40 & 50.74 & 17.39 & -1.60 \\
\hline TP III 6 & 50.59 & 14.93 & 51.42 & 18.38 & -.82 \\
\hline TPZIO & 19.94 & 12.24 & 19.92 & 13.75 & .01 \\
\hline TP Z II 0 & 18.18 & 12.41 & 17.39 & 13.7 & .21 \\
\hline TP Z III 0 & 19.12 & 10.98 & 16.14 & 13.55 & .83 \\
\hline TP Z I 1.5 & 21.43 & 15.28 & 17.08 & 12.46 & 1.05 \\
\hline TP Z II 1.5 & 19.89 & 12.91 & 15.02 & 11.65 & 1.34 \\
\hline TP Z III 1.5 & 20.22 & 12.22 & 14.4 & 11.38 & 1.67 \\
\hline TP Z I 3 & 16.96 & 13.11 & 15.06 & 13.21 & .51 \\
\hline TP Z II 3 & 16.31 & 12.44 & 13.97 & 13.91 & .61 \\
\hline TP Z III 3 & 16.64 & 12.51 & 12.39 & 14.11 & 1.11 \\
\hline TPZI 6 & 16.04 & 11.62 & 14.19 & 13.45 & .51 \\
\hline TP Z II 6 & 14.72 & 10.22 & 14.43 & 13.22 & .08 \\
\hline TP Z III 6 & 14.23 & 10.19 & 13.55 & 14.32 & .18 \\
\hline
\end{tabular}

TP I, TP II, TP III - time estimation: trial 1, trial 2, trial 3, respectively

TP Z I, TP Z II, TP Z III - time misestimation in trial 1,2 and 3, respectively

$0,1.5,3,6$ - estimation of time: initial, 1.5, 3 and 6 hours following the procedure, respectively

eration of time intervals in the first trial 1.5 hour following colonoscopy - the more frequently the studied patients perceived time as ennui and emptiness, the larger the discrepancy between the generated interval and the target one-minute were. Interestingly, there was no significant relation between the perception of time as emptiness and the generation of time intervals on the day preceding colonoscopy.

\section{Discussion}

The primary purpose of this manuscript was to look into the effect on generating time intervals by the patients who were administered general anaesthetics during colonoscopy and to analyze the relationship between perceiving time and the production of one-minute intervals. The postulated hypotheses were partly verified. The first hypothesis concentrated on the impact of general anaesthetics on time interval estimation. The research showed that, contrary to what had been supposed, such substances do not exert any greater influence on the perception of time on the psychophysical level and, what is more, the duration of anaesthesia is also irrelevant. The quick review of the basic results on time production is an optimistic piece of information. Riphaus et al. [34] conducted a study on the influence of short sedation for endoscopic procedures with the application of propofol or midazolam/pethidine. They tested patients 2 hours after anaesthesia and found no differences when tested with the Number Connection Test and a driving simulator. Sanou et al. found that higher cognitive functions (memory, attention, language comprehension and planning) were impaired up to 3 hours after propofol anaesthesia, but recovered 6 hours after it [35]. Interestingly, even elderly patients tested by Kubitz et al. recovered to the baseline results in simple reaction times, critical fusion frequency and short-term memory 2 hours after propofol/remifentanyl anaesthesia, thus proving the usefulness of short-acting anaesthetics in the practice [36].

The second hypothesis, referring to greater dysfunctions in time conception among patients perceiving time as a negative phenomenon prior to colonoscopy, was partly supported. The patients who often 
associate time with boredom, emptiness and nearly pointless existence found it more difficult to generate accurate time intervals, as compared with the patients who seldom thought of time in such terms. We might draw a conclusion that, even if time is seen negatively, but one sees some sense in it and fills it with time-consuming activities, it is possible to regain balance faster after unpleasant experiences. It should be mentioned that high results in the Empty Time scale strongly correlate negatively with the feeling of a sense in life $[12,24]$. There were also interesting differences between the patients experiencing strong anxiety before colonoscopy (i.e. those who were additionally sedated with midazolam) and the patients who were not administered this drug. The patients, who received midazolam, more frequently misestimated time prior to colonoscopy and in the first test after it. Thus, one can say that anxiety exerts a strong influence on the inner clock. Large degrees of misestimation occurred after colonoscopy, solely in the first trial, hence the influence may not have been exerted by the additional sedative, but by the negative emotional state. One can consider the possible residual influence of midazolam on the postoperative performance, although midazolam has a short half-life and small doses used to achieve the similar level of sedation according to Ramsay scale should not affect the Time Production test some hours later.

It is worth to note also that the tested participants of both groups shortened the one-minute intervals. We know from the literature that emotions and cognition are tightly-related items [1]. If we consider the relationship of emotions and perception of time, we know that positive emotion induces impatience and time underestimation (shorter than real). Negative emotion triggers anxiety, gives the experience of time contraction and overestimates time (longer than real) [37, 38]. In the light of the presented data, the participants could have had more positive feelings during hospitalization, because they tolerate the short stay on the ward well. It is probable that the possible therapeutic effect attributed to the colonoscopy was important for emotional state of the patients. One may also say that the very diagnostic process alone (and not the diagnosis nor treatment) relieves suffering and uncertainty communication as a process, but not the final message - as a result of communication. It is also worth remembering that the period of awaiting to be admitted to a clinical ward for diagnosis is usually long in Poland, hence the very admittance into a clinical ward is therapeutically significant. The patient's state can improve just as a result of seeing the end of uncertainty and anticipation which relieves from suffering.

As regards limitations in our study, first and foremost the small population of subjects and an imbalance between the number of participants of each of the sexes. This situation resulted from the considerable reluctance on the patients' side and the definite majority of women among the patients hospitalized on the gastroenterology ward.

\section{Conclusions}

The results show that there were no relations between duration of anaesthesia and the time production. The conception of time as boring and meaningless was linked with larger misestimations of time intervals following colonoscopy. Anaesthesia is an important part of perioperative medicine and there is a growing interest in using anaesthetics in other fields been constantly spreading. The meaning of time perception may become one of its expressions.

\section{Acknowledgements}

\section{Conflict of interest statement}

The authors declare that there is no conflict of interest in the authorship or publication of contribution.

\section{Funding sources}

There are no sources of funding to declare.

\section{References}

1. Salzman CD, Fusi S. Emotion, cognition and mental state representation in amygdala and prefrontal cortex. Ann Rev Neurosci. 2010;3:73-202.

2. Koivula M, Paunonen-IImonen M, Tarkka MT, Tarkka M. Laipalla P. Fear and anxiety in patients awaiting coronary artery bypass grafting. Heart Lung. 2001;30:302-311.

3. Carleton RN, Abrams MP, Asmundson GJG, Antony MM, McCabe RE. Pain-related anxiety and anxiety sensitivity across anxiety and depressive disorders. J Anxiety Disord. 2009;23:791-798.

4. Chundamala J, Wright JG, Kemp SM. An evidence-based review of parental presence during anaesthesia induction and parent/child anxiety. Can J Anesth. 2009;56:57-70.

5. Steinmetz J, Christensen KB, Lund T, Lohse N, Rasmussen LS and the ISPOCD Group. Long-term consequences of postoperative cognitive dysfunction. Anesthesiology. 2009;110(3):548-555.

6. Bschor $T$, Ising $M$, Bauer $M$, Lewitzka U, Skerstupeit $M$, Müller-Oerlinghausen B, Baethge C. Time experience and time judgment in major depression, mania and healthy subjects. A controlled study of 93 subjects. Acta Psychiatr Scand. 2004;109:222-229.

7. Banovic I, Gilibert D, Cosnes J. Crohn's disease and fatigue: Constancy and co-variations of activity of the disease, depression, anxiety and subjective quality of life. Psychol Health Med. 2010;15(4):394-405. 
8. Kamrowska A, Kasprzak K, Marciniak J, Goch A, Kamrowski $C$. Anxiety and depression in ulcerative colitis and Lesniovsky-Crohn's disease. Pol Merkur Lekarski. 2010;28(165):239-241.

9. Buhusi CV, Meck WH. What makes us tick? Functional and neural mechanisms of interval timing. Nature Rev. 2005;6:755-765.

10. Riphaus A, Gstettenbauer T, Frenz MB, Wehrmann T. Quality of psychomotor recovery after propofol sedation for routine endoscopy: a randomized and controlled study. Endoscopy. 2006;38 (7):677-683.

11. Zimbardo, Boyd, 2009, The time paradox. The new psychology of time that will change your life. Atria Books. 2009

12. Nosal C, Bajcar B. Skala orientacji temporalnej AION2000. Podręcznik metody [Temporal Orientation Questionnaire TOQ AION-2000]. 2002.

13. Shmotkin D. The role of time orientation in life satisfaction across the life span. Gerontology: Psychol Sci. 1991;46(5):243-250.

14. Boniwell I, Osin E, Linley PA, Ivanchenko GV. A question of balance. Time perspective and well-being in British and Russian samples. J Positive Psychol. 2010;5(1):2440.

15. Zhang JW, Howell RT. Do time perspectives predict unique variance in life satisfaction beyond personality traits? Pers Indiv Differ. 2011;50:1261-1266.

16. Drake L, Duncan E, Sutherland F, Abernethy C, Henry C. Time perspective and correlates of wellbeing. Time Soc. 2008;17(1):47-61.

17. Boyd JN, Zimbardo PG. Time perspective, health and risk-taking. In Strathman A, Joireman J (Eds.): Understanding behavior in the concept of time: Theory, research, and application (pp. 85-107). Hillsdale, NJ: Lawrence Erlbaum Associates. 2005.

18. Zimbardo PG, Boyd JN. Putting time in perspective: a valid reliable individual differences metric. J Pers Soc Psychol. 1999;77:1271-1288.

19. Block RA, Hancock PA, Zakay D. Sex differences in duration judgments: A meta -analytic review. Mem Cognition. 2000;28(8):1333-1346.

20. Fraisse P. The psychology of time. New York: Harper \& Row. 1963.

21. Aparicio P, Diedrichsen J, Ivry RB. Effects of focal basal ganglia lesions on timing and force control. Brain Cognition. 2005;58:62-74.

22. Rakitin BC, Stern Y, Malapani C. The effects of aging on time reproduction in delayed free-recall. Brain Cognition. 2005;58:17-34.

23. Wittmann M, Carter O, Hassler F, Cahn BR, Grimberg $U$, Spring $P$ et al. Effects of psilocybin on time perception and temporal control of behaviour in humans. J Psychopharmacol. 2007;21(1):50-64.

24. Sobol-Kwapińska M. Kwestionariusz Metafory Czasu. Pracownia Testów Psychologicznych. Warszawa. 2008.

25. Wiggins RD, Higgs PFD, Hyde M Blane DB. Quality of ife in the third age: key predictors of the CASP-19 measure. Aging Soc. 2004;24(05):693-708.

26. Popielski K. Noopsychosomatyka: propozycja nowego podejścia diagnostycznego. Przegląd Psychologiczny. 1999;42(4):17-41.
27. Folstein MF, Folstein SE, Fanjiang G. Mini-Mental State Examination: Clinical guide. Odessa (Florida): Psychological Assessment Resources. 2001.

28. Stanczak J. Krótka Skala Oceny Stanu Umysłowego MMSE (Mini-Mental). Polska normalizacja [Mini-Mental State Examination: Clinical guide for the Polish MMSE normalization]. Warszawa: Pracownia Testów Psychologicznych PTP. 2010.

29. Antonovsky A. Unraveling the mystery of health - How people manage stress and stay well. San Francisco: Jossey-Bass Publishers. 1987.

30. Cartens JA, Spangenberg J. Major depression: in a breakdown in sense of coherence? Psychol Rep. 1997;80(3):1211-1220.

31. Eriksson M, Lindström B. Validity of Antonovsky's sense of coherence scale: a systematic review. J Epidemiol Community Health. 2005;59:460-466.

32. Koniarek J, Dudek B, Makowska Z. Kwestionariusz Orientacji Życiowej (SOC) A. Antonovsky'ego [The Sense of Coherence Questionnaire by A. Antonovsky]. Przegląd Psychologiczny. 1993;36:491-502.

33. Folstein MF, Folstein SE, McHugh PR. Mini-Mental State - a practical method for grading the cognitive state of patients for the clinician. J Psychiatry 1975;12:189-198.

34. Riphaus A, Gstettenbauer T, Frenz MB, Wehrmann T. Quality of psychomotor recovery after propofol sedation for routine endsocopy: a randomized and control study. Endoscopy. 2006;38(7):677-683.

35. Sanou J, Glyn CL, Bourdalle-Badie C, Maurette P. Cognitive sequel of propofol anaesthesia. Neuroreport. 1996;7(6):1130-1132.

36. Kubitz J, Epple J, Bach A, Motsch J, Martin E, Schmidt $\mathrm{H}$. Psychomotor recovery in very old patients after total intravenous or balanced anaesthesia for cataract surgery. BJA 2001;86(2):203-208.

37. Angrilli A, Cherubini P, Pavese A, Manfredini S. The influence of affective factors on time perception. Percept Psychophys. 1997;59:972-982.

38. Droit-Volet S, Gil S. The time-emotion paradox. Phil Trans R Soc B. 2009;364:1943-1953.

Acceptance for editing: 2015-04-29 Acceptance for publication: 2015-05-28

Correspondence address: Włodzimierz Płotek
Department of Teaching Anaesthesiology and Intensive Therapy

Poznan University of Medical Sciences 14 Marii Magdaleny Str., 61-861 Poznań, Poland phone: +48616687836; fax: +48616687860 e-mail: plotekw@poczta.onet.pl 